\title{
New Hysterectomy Technique with Correction of Stress Urinary Incontinence, and Mixed Urinary Incontinence
}

\author{
Oscar Raúl Muñoz Angel \\ Gynecology Department, Hospital "Raúl Orejuela Bueno”, Palmira, Colombia
}

Email address:

ormange162@hotmail.com

\section{To cite this article:}

Oscar Raúl Muñoz Angel. New Hysterectomy Technique with Correction of Stress Urinary Incontinence, and Mixed Urinary Incontinence. Journal of Gynecology and Obstetrics. Vol. 9, No. 3, 2021, pp. 75-78. doi: 10.11648/j.jgo.20210903.14

Received: May 21, 2021; Accepted: June 16, 2021; Published: June 22, 2021

\begin{abstract}
Statistically, 50\% or more of the patients who are going to be hysterectomized have stress, urgency and mixed urinary incontinence, a problem that, when presenting significantly high figures in its epidemiology, requires finding a treatment that promises a cure for this pathology, since it represents not only a global public health problem for women, but also a global burden, for example, in the US for the treatment of urinary incontinence there has been an annual expenditure of more than 26 billion dollars. This article provides evidence that allows proposing the Hysterectomy + cysto-urethro-colpus suspension surgical technique - SYCFIM, as a treatment for stress and mixed urinary incontinence. A study was carried out with 6 patients with uterine pathology associated with urinary incontinence. A pre-surgical urodynamics were performed, finding one patient with stress incontinence and five patients with mixed incontinence. At the postoperative control appointments at two weeks and two months, the patients reported the disappearance of incontinence. And at two years and five months, they continued without urinary incontinence in $100 \%$ of the cases. The results of the urodynamics performed at two years and five months, demonstrated the disappearance of stress incontinence in $100 \%$ and mixed in $100 \%$, thus confirming that the SYCFIM technique works as a treatment for stress and mixed urinary incontinence.
\end{abstract}

Keywords: Hysterectomy, Stress Urinary Incontinence, Mixed Urinary Incontinence, Sycfim Suspension, Urodynamics, World Pathology

\section{Introduction}

Urinary incontinence (UI) is defined by the International Continence Society (ICS) [1], as any involuntary loss of urine. It is an extraordinarily frequent condition and its increase in prevalence is closely linked with age, which constitutes an important medical and social problem due to the high incidence worldwide, given the increase in the average life span at present.

Reports from the United States estimate that more than 600,000 women undergo hysterectomy each year, where the age group to which they belong has an incidence of more than $40 \%$ of UI, which indicates that 240,000 women who must be operated with the hysterectomy technique correct the UI. In contrast, studies report that the traditional hysterectomy technique would increase UI by 2.5 times [2].

UI is a global health problem that has not been made visible despite the high numbers of UI, which should be considered a public health problem for women; $70 \%$ of women are ashamed to show their incontinence in the consultation, which leads to poor identification and diagnosis. Studies explain that most women do not talk to their doctor about their symptoms out of embarrassment, due to the perception that UI is a "normal" part of aging, or that they are sequelae of hysterectomy [3].

Figures for the prevalence of UI in the UK are equally high, at $69 \%$, in Norway at $25 \%$, and $36 \%$ in countries such as France, Germany, Italy, Spain, and Sweden. [4, 5, 6].

UI has been shown to negatively impact areas such as social relationships, work, travel, sports, sexuality, and hobbies, as well as how the problem impacts your life and the people around you. $[4,7]$.

The impact on health-related quality of life by UI may even be greater than that caused by some chronic diseases such as diabetes or high blood pressure [8].

Studies show that up to $91 \%$ of women who attended a urodynamics clinic reported that UI symptoms affected at least three of the following: physical health, mental well- 
being, housework, social life, sexual life, relationships with family or partner, work, used clothes and fear of smell $[9,10$, $11]$.

Another important aspect of urinary incontinence in women as a global burden, is indisputably the increase in billionaire expenses dedicated to their medical treatment. Studies show spending of \$ 16.3-26 billion in annual direct care related to urinary incontinence in the US [12, 13].

It has been revealed that in developed countries at least $2 \%$ of the health budget (diagnostic and treatment costs) is devoted, and $90 \%$ is devoted to disposable products [14].

Similarly, estimated UI costs in the UK range from $£ 354$ to $£ 536$ million. Women living in the community incur $70 \%$ of the costs $[15,16]$. The medical cost of a woman with stress UI is 1.8 times higher than that of a woman without a UI. Swedes spend 925 million SEK annually on treating this pathology [17].

Since the birth of medicine, the clinical history is the method by which diseases, syndromes, disorders are diagnosed, through the identification of the patient's symptoms; It is an investigative process oriented to the diagnosis based on the integration of the symptoms, signs of the physical examination and other data provided by the anamnesis and the clinical interview that serve as a guideline and procedure of the treatment [18].

The literature that studies urodynamics refers that despite its usefulness and its significant acceptance in the field of medical diagnosis, it also shows that it can be replaced by the clinical history provided by the patient on their symptoms and their ultrasound. Against this, evidence provided by medical research can be mentioned. A prospective and randomized study of 80 women with SUI, who were taken to a suburethral sling, where 40 women were evaluated preoperatively with urodynamics and the other 40 were not performed. Cure of stress incontinence was found in 39 of the $40(98 \%)$ who underwent urodynamics, against 38/40 $(95 \%)$ of the patients who did not undergo urodynamics. Which concluded that the lack of urodynamic study did not adversely affect the results of surgery [19]. Another study showed that the use of urodynamic tests in women with UI improved the effectiveness of the treatment only by $0.06 \%$ (from $96.37 \%$ to $96.43 \%$ ), also finding that the basic clinical evaluation was more effective in economic terms than the urodynamic test when the pure SUI prevalence is $81 \%$ or higher [20].

Clearly, scientific research uses the evaluation method of the clinical history to determine the efficiency and efficacy of the urodynamic study [21]. Once UI disease has been diagnosed, surgical correction is the most effective method of treatment for stress urinary incontinence (SUI) among the different therapeutic options currently available; It is estimated that there are more than 100 urethropexy techniques, which are performed vaginally, suprapubically, laparoscopically or in combination, with highly variable clinical and urodynamic results [22].

Reviewing the scientific literature, it is found that there are multiple surgical treatments for SUI, but not many surgical techniques are identified to correct mixed urinary incontinence. Only two techniques are reported: One, is the retropubic dome suspension, of this surgery there is a descriptive and cross-sectional study with 60 patients with mixed incontinence, attended in the Urology consultation of the Provincial Surgical Clinical Teaching Hospital "Saturnino Lora Torres" in Santiago from Cuba. This study revealed that after 9 months a continence of $87.5 \%$ was obtained. This allowed us to conclude that retropubic suspension is a highly effective procedure for treating patients with MI. [23].

The other surgical treatment consists of fixing the fascia to the midline dome (colpococystopexy), associated with the Burch for the treatment of cystocele and mixed urinary incontinence [24].

The most extensive and detailed investigation of the causes of SUI and SUI show that the ideal surgical technique is the surgical technique that restores the anatomical position of the vesico-urethral system and does not injure supporting structures [25], which is achieved with the technique SYCFIM.

\section{Methodology}

This article corresponds to a controlled clinical trial, using the new SYCFIM hysterectomy surgical technique in the intervention.

A prospective study was carried out in 6 patients with incontinence diagnoses, one of the patients was diagnosed with stress urinary incontinence, and five patients with mixed urinary incontinence. The age range of the patients was 45-60 years, with a weight range of 62-70 kilograms and a height of $150-156$ centimeters.

Studies prior to urodynamic and urine culture surgery were carried out in the period between 03/14/2017 and 08/20/2018, and post-surgical urodynamic and urine culture studies were performed on 07/09/2020, in the department of urology at the Mario Correa Rengifo Hospital in Cali, Colombia.

The urodynamic results prior to surgery were of 5 patients with SUI and 1 with SUI.

Subsequently, the 6 women underwent the SYCFIM surgical technique at the Raúl Orejuela Bueno Hospital in Palmira-Colombia. Surgery performed by a gynecologist and assistant (general practitioner), on the dates between 06/01/2017 and 10/25/2018.

The postoperative control at two weeks showed the disappearance of UI and UI, and two months after surgery the disappearance of SUI and UI persisted clinically.

Finally, after an average of 2.5 years after surgery, urine cultures and urodynamics are performed again, showing the resolution of urinary pathology in all patients with stress and mixed urinary incontinence.

The SYCFIM technique respects the original anatomy of the pelvic structures (intrafacial + fixation of rounds to the dome) and a new urethro-vesical support (fixing the dome to the abdomino-pelvic fascia). Thus, a urethro-cysto-colpopexia is generated, by renewal of the support with the union of round - sacral - cardinal ligaments and dome. And 
reinforcement of the bra, fixing the cupola to the abdominopelvic fascia.

It consists of not eliminating the supporting structures that have always served this purpose, but rather of reusing them, and using them as a new reinforcement. The dome fixation to the abdominopelvic fascia is done with a non-absorbable suture, which will provide stability and permanent support.

The technique is developed following the following steps: 1. The round ligaments are fixed to the lateral edge of the dome, on the side that corresponds to the ligament with nonabsorbable suture, 2. Continuous suture is continued on the dome (4 points until reaching the opposite end), 3. Fixation of the second round ligament is made, 4 . Then the suture is continued exiting the pelvic cavity to the abdominopelvic fascia, furthest from the midline, 5. Continuity points are placed on average of six, until reaching the other side of which it exited, 6. The abdominal-pelvic cavity is re-entered, and the suture is fixed at the anterior junction of the round dome. 7. Finally the edge of the bladder is attached to the dome.

\section{Results}

The patient with stress urinary incontinence reported the disappearance of the pathology 2 months after surgery, and at 2.5 years the disappearance of UI was confirmed clinically and by urodynamics.

The group of five patients with mixed incontinence reported the disappearance of the pathology 2 months after surgery, and at 2.5 years the disappearance of the mixed incontinence was confirmed clinically and by urodynamics.

There were no intra- or extra-operative complications, or collateral effects to the surgical technique used.

\section{Discussion}

Stress urinary incontinence has multiple surgical treatments, but for the treatment of mixed urinary incontinence the options are almost nil. The main cause is the establishment of the origin of said pathology, thus generating the impossibility of surgical treatment.

Although there is little pronouncement in the association of SUI and SUI, the statistics of these pathologies and association with age, generate evidence of the causality is the deterioration of the supporting structures.

It is the visualization of the association of age and its logical consequences of neuro-anatomical deterioration that allows to show that the traditional pexia of the cysto-urethral junction, (it is generally the surgery that is performed), does not manage to reestablish the original anatomy of the voiding component, unlike SYCFIM, which performs a urethro-cystcolpus pexia, thereby achieving the original anatomical restoration of the entire urinary system at the pelvic level. The neuromuscular component is almost entirely restored by kegel exercise.

The SYCFIM technique has a minimum degree of complexity and postoperative complications, since there is total visualization of the structures, which are those involved in the correction of SUI, UI, and UI, such as: the cupola, the bladder, the round ligaments, and the fasciae.

Although the study was carried out with few patients, it is carried out to respect the most recognized protocol for the diagnosis of MUI, which is urodynamics.

In the last 5 years I have performed the SYCFIM technique in more than 120 patients with a clinical diagnosis of MUI confirmed by an interview conducted by the psychologist of the Universidad Pontificia Bolivariana and the disappearance of the pathology in $99 \%$ of cases after surgery. This article projects a real and logical alternative to cure SUI, UUI and SUI, in patients who present one of these pathologies and are scheduled for hysterectomy or having the same principles for the patient in whom the hysterectomy has already been performed and present UI.

\section{Conclusions}

In this research, to verify the credibility of the SYCFIM technique that cures UI, the concepts of the foundation of urodynamics for the diagnosis of UI were respected, performing pre and postoperative urodynamics.

Currently, there are surgical alternatives that generate high-cost overruns, some already ruled out due to secondary complications or the use of materials that cause pathologies, the SYCFI on the other hand generates an additional cost of 3 dollars in suture materials and is easy to perform in the treatment of hysterectomies associated with urinary incontinence.

SYCFI makes the disappearance of the UI since it performs anatomical restoration of the structures involved in urination. This is a technique that can be used to heal both stress UI and mixed UI.

\section{Acknowledgments}

To all the patients who during the last 14 years allowed to develop this technique and to whom I owe the knowledge of the achievements of the dome pexia, which begins when I do not remove the round ligaments, but fix them again to the dome (at place the fixation points, a one centimeter cut is made to the ligament, and therefore a urethro-cysto-colpos pexia) and many patients stated: "Thank you doctor for curing me from urinary incontinence without having told you that I had it.". Thus began the path of knowledge of urinary incontinence in women and its treatment.

\section{References}

[1] Abrams P, Cardozo L, Fall M, Griffiths D, Rosier P, Ulmsten $\mathrm{U}$ et al. The standardistation of term urinary tract function: report from the standardistation subcommittee of the international neurourol Urodyn 2002; 21: 167-178.

[2] Altman D, Granath F, Cnattingius S, Falconer C. (2007). Histerectomía y riesgo de incontinencia urinaria de esfuerzo quirúrgica. The Lancet, 2007. 307: 1494-99. 
[3] Fultz NH, Herzog AR. Self-reported social and emotional impact of urinary incontinence. $J$ Am Geriatr Soc 2001; 49: 892-9.

[4] Swithinbank LV, Abrams P. The impact of urinary incontinence on the quality of life of women. World $J$ Urol 1999; 17: 225-9.

[5] Hannestad YS, Rortveit G, Sandvik H, Hunskaar S. A community-based epidemiological survey of female urinary incontinence: the Norwegian EPINCONT study. Epidemiology of Incontinence in the County of NordTrondelag. J Clin Epidemiol, 2000; 53: 1150-7.

[6] Milsom I, Abrams P, Cardozo L, Roberts RG, Thuroff J, Wein AJ. How widespread are the symptoms of an overactive bladder and how are they managed? A population-based prevalence study. BJU Int 2001; 87: 760-6.

[7] Melville JL, Delaney K, Newton K, Katon W. Incontinence severity and major depression in incontinent women. Obstet Gynecol 2005; 106: 585-92.

[8] J. E. Robles. La incontinencia urinaria. An. Sist. Sanit. Navar. 2006; 29 (2): 219-232.

[9] Norton C. The effects of urinary incontinence in women. Int Rehabil Med 1982; 4: 9-14.

[10] Huaman Gurrrero M, Grado de depresión asociado a incontinencia urinaria en mujeres en el Hospital Daniel Alcides Carrión, en el mes de noviembre a diciembre del 2018 Tesis de grado-Universidad Ricardo Plama; Lima Peru; 2018, 43.

[11] Valencia Orgaz P, Calidad de vida en la mujer con incontinencia urinaria y papel del profesional sanitario y de la paciente, dentro del marco asistencial de atención primaria en la Comunidad de Madrid; tesis doctoral - Universidad Computense de Madrid; 2015, 273.

[12] Wagner TH, Hu TW. Economic costs of urinary incontinence in 1995. Urology 1998; 51: 355-61.

[13] P. B. Minner. Economic and personal impact of fecal and urinary incontinence. Gastroenterology, 126 (2004), pp. 8-13.

[14] J. W. Thüroff, P. Abrams, K. E. Andersson, W. Artibani, C. R. Chapple, M. J. Drake, et al. EAU guidelines on urinary incontinence. Eur Urol, 59 (2011), pp. 387-400.

[15] Wilson L, Brown JS, Shin GP, Luc KO, Subak LL. Annual direct cost of urinary incontinence. Obstet Gynecol 2001; 98: 398-406.

[16] Hu TW, Wagner TH, Bentkover JD, Leblanc K, Zhou SZ, Hunt T. Costs of urinary incontinence and overactive bladder in the United States: a comparative study. Urology 2004; 63: 461-5.

[17] Peyrat L, Haillot O, Bruyere F, Boutin JM, Bertrand P, Lanson $Y$. Prevalence, and risk factors of urinary incontinence in young and middle-aged women. BJU Int 2002; 89: 61-6.

[18] Holroyd-Leduc JM, Tannenbaum C, Thorpe KE, Straus SE. What type of urinary incontinence does this woman have? JAMA 2008; 299: 1446-56.

[19] Choe, J. M., Frankl, N.: Sling Surgery performed with and without preoperative urodynamics: a comparative outcomes analysis. Annual meeting AUA 2001.

[20] Weber AW., et al.: Cost-effectiveness of preoperative testing for stress urinary incontinence in women. Annual Meeting AUA 2000

[21] Espejo Pezzini JA, (2007). Evaluación urodinámica de la incontinencia urinaria de esfuerzo en mujeres atendidas en el hospital Alberto Sabogal Sologuren EsSalud-Callao. Trabajo de investigación para optar al tíitulo de urología Universidad del peru; 2007, 26.

[22] Resel E, Bocmwo G, Moreno J, Redondo J, Corral J. (2000). Tratamiento quirúrgico de la incontinencia urinaria femenina de esfuerzo. Clínicas litológicas de la Complutense, 8, 395423, Servicio de Publicaciones. UCM, Madrid 2000.

[23] Mirabal Fariñas A, Meléndez Borges JE, Pouyot Castillo A, Ferrer La O C, and Milán Barreiro R. (2014). Suspensión retropúbica en mujeres con incontinencia urinaria de esfuerzo; MEDISAN vol. 18 no. 9 Santiago de Cuba set.-set. 2014.

[24] Serrano EA, Lorenzo JL, López VA, Montoya G, Orozco JC, Ixquiac GA. (2009). Uraco-cistopexia: nueva técnica de cistosuspensión asociada al Burch para el tratamiento del cistocele e incontinencia urinaria de esfuerzo, seguimiento a largo plazo. Arch. Esp. Urol. vol. 62 no. 1 ene./feb. 2009.

[25] B. Liedl1, O. Markovsky1, F. Wagenlehner2 and A. Gunnemann (2012). The Role of Altered Connective Tissue in the Causation of Pelvic Floor Symptoms 1Pelvic Floor Centre Munich, 2Urological Clinic of the University of Giessen, Urological Department Klinikum Detmold, Germany. 